\title{
Melilla en el período comprendido entre febrero y julio de 1936
}

Juana Alias Rodriguez

El 15 de enero de 1936 se firmó el pacto del Frente Popular. Los puntos que destacaban en su programa eran:

-Amnistía general.

- Reintegración de represaliados.

- Puesta en vigor de la Reforma Agraria.

- Reforma de las leyes Municipal, Provincial y de Orden Público.

-Derogación de la Ley de Arrendamientos.

- Reorganización de la Jurisdicción del Trabajo.

-Impulsión de la primera y segunda enseñanza.

-Democratización de la enseñanza universitaria.

Los firmantes eran: Unión Republicana, Izquierda Republicana, PSOE, PCE; UGT, Federación de Juventudes Socialistas, Partido Sindicalista y POUM.

Por su parte la derecha formó un frente encabezado por CEDA y Bloque Nacional.

La noche del 16 de febrero se supo que el Frente Popular ganaba en todas las ciudades de más de 150.000 habitantes; de madrugada que el triunfo se extendía a 31 circunscripciones.

Las elecciones de febrero de 1936

Suponen la culminación de una intensa campaña electoral, en la que los diferentes partidos que en ella participan realizan gran cantidad de actos propagandísticos, encaminados a la consecución del mayor número de votos.

En Melilla, la campaña se desarrolla en un clima de efervescencia de mítines y asambleas pero de impecable calma y ausencia significativa de alteraciones de orden. Los principales actos que se realizan son los siguientes:

-2 de febrero: Mitin de la Federación de Sindicatos Unidos (C.N.T.) en el Cine Alhambra.

-4 de febrero: Asamblea de los elementos de la Juventud del partido de Unión Republicana, saliendo elegido el nuevo Comité Directivo.

-6 de febrero: Mitin del Partido Sindicalista Español en el Cine Goya.

-9 de febrero: Acto público, en el Cine Perelló, organizado por la Coalición 
del Frente de lzquierdas, con la intervención de miembros del Partido Comunista, Partido Sindicalista Español, Partido Demócrata Federal, Izquierda Republicana, Partido Socialista y del Candidato a diputado don Luis Barrena.

Con anterioridad, el partido Unión Republicana de Melilla, habia sido designado por el Comité Ejecutivo de Enlace de Madrid para nombrar el candidato diputado a Cortes de la Coalición de Izquierdas en Melilla. En la noche del 1 de febrero, fue nombrado por mayoría de votos de la Asamblea el correligionario don Luis Barrena y Alonso de Ojeda, abogado criminalista de profesión.

El partido de derechas, Acción Popular, comienza a insertar en la prensa, con la misma fecha, propaganda de su candidato Emilio Hermida Rodríguez, candidatura que no fue mantenida, por dificultades en cuanto a los gastos de la campaña, dejando dicho partido en libertad de voto a sus afiliados y simpatizantes.

Sin embargo, la Asociación Femenina del mismo partido pide el voto para el candidato de Centro-Derecha don Carlos Echeguren, que era el anterior diputado por la ciudad y había sido nominado el 17 de enero en Asamblea del Partido Radical.

Con motivo de la conmemoración de la $1 .^{a}$ República Española, el día 11 de febrero, se celebraron actos en casi todas las sedes de asociaciones y partidos políticos de la ciudad, con la exaltación en todas ellas de la figura del general Villacampa.

El día 16 de febrero, se realiza la consulta electoral con los siguientes resultados:

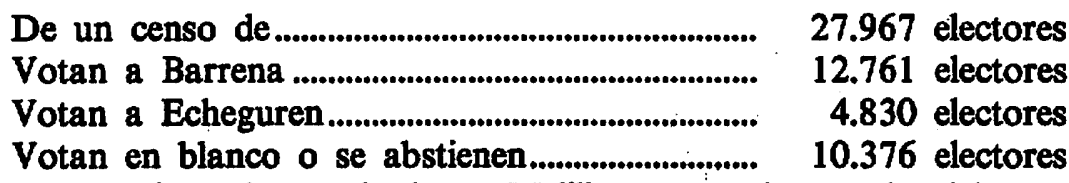

Las cifras que arrojaron los resultados en Melilla, concuerdan con las del resto del territorio nacional, con clara ventaja del Frente Popular y a partir de aquí la actividad se aceleró en entidades y organismos oficiales a fin de poner en marcha las disposiciones del nuevo gobierno con miras al cumplimiento y realización de los objetivos propuestos en la campaña electoral.

Toma de posesión de los concejales destituidos y primeras medidas municipales

Hay que destacar, que en cuanto se tuvo noticia de la dejación de poderes del gobierno Portela, el Delegado de Gobierno señor Miguel, se marchó precipitadamente a la península a través de la zona del Protectorado, resignando el mando en su sustituto el Juez de Instrucción don Fernando Gamarra.

Es por tanto, este personaje, en su calidad de Delegado interino, quien publicó la siguiente nota: "En virtud de órdenes recibidas del Ministerio de la Gobernación, a las cuatro de la tarde de hoy, celebrará sesión extraordinaria el Excmo. Ayunta- 
miento, con el fin de reponer en sus cargos a los concejales de elección popular destituidos en octubre de 1934."

En el día y la hora señalados se celebró la anunciada sesión del Ayuntamiento, presidida por el Delegado interino de Gobierno y con la asistencia del Alcalde señor García Vallejo, Tenientes de Alcalde señores Fernández de Castro y Espona, Concejales señores Solís, Garcia Fajardo, Caro, Martín Figueras Benchimol, Navarro y Martínez González y los Concejales repuestos señores Diez, Hernández Quirantes, García Dómine, Orte, González Doña, Vicente, Rutllant y Torezano.

Esta sesión tuvo una importancia muy significativa, no sólo por las palabras que pronunció Antonio Diez, en nombre de la Minoría Socialista, en cuanto a unas futuras depuraciones de responsabilidad, sino también por los acontecimientos que en la calle estaban teniendo lugar.

Mientras tenia lugar la celebración de la sesión, en el Ayuntamiento, en los alrededores del mismo, se congregó una multitud entusiasmada que aclamaba a los concejales repuestos y al diputado electo. Por ello, al finalizar la sesión, los señores Díez y Barrena, hablaron al gentío desde el balcón del Ayuntamiento, exhortándoles a que observen el más estricto orden, haciendo mención a la liberación de los presos.

A continuación se realizó una imponente manifestación, que recorrió la ciudad en medio del mayor entusiasmo, ya que mucho antes de las cuatro de la tarde en la plaza del Comandante Benitez se habian ido congregando agrupaciones políticas y sociales de izquierdas. Recorrieron la Avenida de la República, Plaza de España, llegando al Ayuntamiento con monumentales retratos de Pablo Iglesias, Azaña, así como otro del Presidente de Unión Republicana Martínez Barrio. A partir del Ayuntamiento, la multitud siguió por distintas calles, yendo al frente de la misma el diputado señor Barrena y concejales repuestos.

Durante la manifestación tuvo lugar un incidente violento, ya que un individuo arrojó sobre la puerta del Sagrado Corazón un cubo con materia inflamable, que produjo un conato de incendio. Bste incidente se achacó a las Juventudes Unificadas por un sector de la opinión, mientras que por otro se inculpó a un sacerdote de la mencionada parroquia.

La violencia volvió a manifestarse al término de la misma cuando grupos aislados se dirigieron a la sede del Partido Radical, causando daños en muebles y enseres. Igualmente ocurrió en la sede de Acción Popular.

Al día siguiente se convocó una nueva sesión en el Ayuntamiento, en la cual dimitió el alcalde señor Vallejo, eligiéndose como nuevo alcalde a don Antonio Diez. En su primera alocución como tal, se reiteró en las acciones de depuración dirigidas en primer lugar hacia miembros de la Guardia Municipal, así como manifestó su preocupación por paliar el paro existente en la ciudad.

Los señores Espona, Benchimol, Alvarez de Castro, Navarro y Rodríguez, ofrecieron su sincera y espontánea colaboración para "laborar con el mayor entusiasmo por el pueblo de Melilla".

Ateniéndonos al contenido de las Actas de las Sesiones Municipales, podemos afirmar que estos concejales anteriormente nombrados, asistieron con regularidad 
a todas las sesiones que se celebraban semanalmente, sin oponerse tajantemente a ningún proyecto presentado por la mayoría dominante en el Ayuntamiento. Unicamente se llegó a pedir la suspensión de algún proyecto para un estudio más detenido del mismo.

Existía, sin embargo, un grupo de concejales, que apenas asistian a las sesiones, ante estas reiteradas faltas, el alcalde propuso un sistema de multas y para casos de reincidencia la aplicación del artículo 189, por el cual el Delegado de Gobierno debía ser notificado de estas faltas.

Todas las disposiciones y proyectos solían salir adelante por mayoría de votos. Reflejo de esta situación son las propias palabras del alcalde: "Se ha dicho que esto es una dictadura y yo la acepto si esta dictadura la empleo en bien de Melilla."

Al igual que en el resto de España, se suscitó el problema de sustituir a los funcionarios que habían obtenido puestos por oposición en el Ayuntamiento desde octubre de 1934. Tomado como modelo el Ayuntamiento de Granada, se siguen las disposiciones de este último y se destituyeron los funcionarios afectados por la medida, desestimándose un recurso interpuesto por dichos funcionarios.

\section{Los problemas económicos}

Se había solicitado con insistencia al gobierno la supresión del Impuesto de Utilidades. El 25 de febrero, el Presidente del Consejo de Ministros, comunicó a la ciudad, que no estaba exenta de contribuir al mencionado impuesto por ninguna Ley.

Otro nuevo problema vino a añadirse a los ya existentes, al implantarse el $12,5 \%$ de los Derechos de Aduanas en el puesto de Beni-Enzar, por unificarse la tarifa en todo el territorio marroquí. El alcalde pidió al pueblo de Melilla el envio de telegramas al Gobierno solicitando el "statu quo" hasta primeros de año.

El dia 9 de abril, reunido el Ayuntamiento en sesión extraordinaria, se trató acerca del régimen económico que necesitaba la ciudad, aduciéndose que con el nuevo impuesto se iba a crear una situación de inferioridad de la misma con el resto de España.

En este aspecto se pide a las entidades que radican en Melilla expongan sus soluciones que propicien una mejora en la población.

Por parte de la alcaldía se proponen dos soluciones para dar término a la situación por la que se atraviesa:

- Por un lado la Reforma Fiscal de la ciudad suprimiendo la caseta de Aforos.

- Por otro lado un Concierto Económico con el Estado.

Ante la inviabilidad legal del primer supuesto, se acordó convocar un plebiscito, para poder conseguir del Estado un Concierto Económico especial debido a las singulares características de la ciudad.

Se realizó una intensa propaganda para conseguir la participación masiva de la población en el mismo, que giraba en los siguientes términos:

"Vecino de Melilla, tú que pasas hambre por falta de trabajo, tú que no vendes tus productos porque estás agobiado de cargas, tú cuyas rentas ves amenazadas 
por cargas presupuestarias nuevas; vosotros todos: obreros, comerciantes, propietarios, no podéis ver con indiferencia el porvenir de Melilla. Para resolver tan magno problema, toma parte activa en el Plebiscito Pro-Concierto Económico con el Estado, que se celebrará el día 14 de junio en todos los colegios".

Efectuada la votación en el día mencionado y una vez hecho el recuento de los votos, el resultado es favorable a la propuesta municipal por un $65 \%$ a favor.

Con el respaldo del consenso popular el Alcalde se desplazó a Madrid donde desarrolló una gran actividad ante los organismos pertinentes.

Una vez de vuelta en Melilla dio cuenta de su actuación en la sesión del 27 de junio. Manifestando sus quejas en el sentido de que en las diferentes gestiones realizadas en la capital de la República, pudo comprobar personalmente el desconocimiento absoluto en relación a los problemas de nuestra ciudad.

Sin embargo, consiguió de don Indalecio Prieto el ofrecimiento de defender en las Cortes el Proyecto sobre el futuro Régimen Económico de la Ciudad.

Esta supone, sin duda, la última gestión realizada por el alcalde pues pocos días después presentó su dimisión aduciendo motivos de enfermedad. Su propio partido publicó una nota en prensa, aclarando, que su dimisión no se debía a una medida disciplinaria, sino de política interna de partido.

En estos primeros dias de julio, son varios los concejales pertenecientes a partidos integrantes del Frente Popular que se dan de baja en sus respectivos partidos. En la semana escasa que media entre la dimisión del alcalde y el 17 de julio no se eligió uno nuevo, se daba como candidato al puesto al ex-sacerdote Diego Jaén.

\section{Problemática social}

Como principal exponente de este tipo de problemas, existe no sólo en la ciudad sino en todo el territorio nacional, la grave situación por la que atraviesa el elevado número de afectados por el paro.

En Melilla la situación presentaba características especiales debido a la gran cantidad de inmigrantes, llegados en su mayor parte del sur de la Península y de Levante.

Se acentuó este hecho, al derogarse el Real Decreto que condicionaba la entrada de obreros en las Plazas de Soberanía del Norte de Africa. Aparte de ello, existía en la ciudad un comedor popular gratuito en el que llegaron a repartirse 2.000 raciones diarias; a los obreros, sin contarles tiempo de residencia; se les facilitaba por el municipio asistencia médico-farmacéutica, siendo igualmente gratuitas las hospitalizaciones en la Cruz Roja.

A principios de marzo, las autoridades de la Zona Francesa, redujeron en un $30 \%$ los vehículos en circulación en la misma. Ello produjo una masiva afluencia de estos nuevos parados hacia nuestra ciudad. El Delegado de Gobierno rogó a los obreros de la Plaza que no trajeran a familiares suyos, aduciendo que había que acabar con la leyenda de que en Melilla, con el comedor popular y una barraca se 
vive admirablemente, dictando, con fecha de 12 de marzo, nuevas normas para la entrada de obreros en la ciudad.

Para paliar en lo posible el paro obrero, el Ayuntamiento inició medidas tales como el asfaltado de varias calles, se estudió la traída de aguas de Trara considerando insuficiente la cantidad asignada por el Gobierno para tal fin, por lo que se asignó además una cantidad suplementaria. En su viaje a Madrid, consiguió el Alcalde, la cantidad de $\mathbf{5 0 . 0 0 0}$ pesetas para acometer trabajos de repoblación forestal, asi como también la muy importante cantidad de $\mathbf{2 0}$ millones para la construcción del Dique Sur.

Como todas estas medidas resultaron insuficientes debido a la muy elevada cantidad de parados que existian, el Delegado de Gobierno propuso a finales de mayo una nueva solución, consistente en unas aportaciones de carácter voluntario para conseguir un fondo para remediar el paro obrero. Se realizó un baremo de cotizaciones, publicándose la cantidad que correspondía pagar a entidades y particulares, según su situación específica, aclarándose que con estas aportaciones se pretendia dar trabajo a todos los obreros parados sea cual fuere su ideología.

Las listas de contribuyentes empiezan a aparecer en la prensa local los primeros días de junio, consignándose a diario las cantidades aportadas y la suma total de lo recaudado. Las entregas de dinero para este fin, no se interrumpieron tras el 17 de julio, fecha del Alzamiento en la Plaza, sino que las listas acompañan simultáneamente a las de entregas de joyas, ropas y dinero para los combatientes en zona nacional.

Otro aspecto muy importante de la problemática social de este período, lo representa la conflictividad laboral entre obreros y patronos y entre las distintas Asociaciones Laborales y Entidades Sindicales.

En este sentido destacan las acciones propuestas por las organizaciones sindicales C.N.T. y F.A.I., llegando a prohibir mediante comunicado a los comerciantes el desembarco de muebles procedentes de la Península, exhortando a los almacenistas del ramo a fundar talleres de construcción en la Plaza.

Son numerosas las protestas que se produjeron ante este tipo de iniciativas, sobre todo por parte de la Unión Gremial y de la Cámara de Comercio, Industria y Navegación de la ciudad.

La conflictividad laboral fue aumentando progresivamente a lo largo de este período, destacando las huelgas en los sectores metalúrgico, carga y descarga y sobre todo en el sector de panadería.

No se llegaron a producir situaciones dramáticas como en otros lugares de España pero el conflicto del ramo de panadería, que se había iniciado a mediados de marzo se fue agravando progresivamente hasta el comienzo de la Guerra Civil. Los Jurados Mixtos exigían de los patronos panaderos, la sustitución de los obreros en el día de descanso semanal por obreros profesionales. Ante la negativa a acatar esta norma, algunos son multados por la autoridad gubernativa, llegándose a la detención de varios, así como también a la incautación de 6 tahonas en los días 15 y 16 de julio.

Durante los primeros días de julio al número de huelgas aumentó constante- 
mente: Obreros del ramo de pintores de C.N.T. y U.G.T., obreros de carga y descarga, metalúrgicos..., etc. Por ello, la U.G.T. local, ante el caos laboral reinante y la cantidad de consignas emitidas desde los más diferentes ámbitos ideológicos, recomendó a sus afiliados no atendieran otras órdenes que las emanadas de dicha federación, ni se hicieran eco de las incitaciones, que con fines oscuros partian de diversos origenes.

En todo este periodo existe un gran interés por parte de las autoridades, en que se readmitan los obreros despedidos en octubre de 1934 y en 1932, consiguiéndose la readmisión de los primeros, sin apenas incidentes en marzo, incluso antes de aparecer oficialmente ninguna disposición en este sentido.

Alteraciones del orden público

El Delegado de Gobierno a poco de tomar posesión de su cargo, y en previsión a posibles hechos violentos, publicó un edicto, por el cual caducaban todas las licencias de armas.

A finales de marzo, por parte de la autoridad gubernativa se detuvo a varios dirigentes de Falange Española, incautándosele la correspondencia que venía dirigida a los directivos.

El 25 de marzo, se produjo un atentado contra las personas de don Ramón Morán y don Rufino Hidalgo cuando ambos se encontraban circulando por la calle O'Donnell y unos desconocidos les dispararon en el muslo y tobillo respectivamente. Se detuvo en esta ocasión a dos individuos que quedaron posteriormente en libertad por falta de pruebas.

De una agresión, fue asimismo objeto el director de "La Vanguardia" órgano de Acción Popular, don José Sánchez Rueda durante la noche del 4 de marzo a las puertas de su domicilio en la calle del General Aizpuru.

La fiesta del 1 de mayo, se realizó con gran solemnidad, celebrándose un brillante desfile en el que participaron representantes de las Sociedades Obreras con sus emblemas y estandartes en cabeza. Al finalizar el desfile, por elementos no identificados, se procedió al asalto de las oficinas y el almacén que en la calle Chacel tenía la Sociedad Canariense, concesionaria en Melilla y Ceuta del Monopolio de Tabacos, viéndose obligada una patrulla de carabineros a disparar sus armas al aire, no pudiendo evitar, sin embargo, algunos destrozos y desaparición de mercancias almacenadas.

Ese mismo día se produjeron disparos desde una azotea en el edificio de la Notaria, sin mayores consecuencias que la natural alarma que produjo el hecho.

Aparte de estos acor tecimientos reseñados, no existieron mayores alteraciones de orden público, que algunos altercados callejeros entre miembros de partidos de distinta ideologia sin alcanzar en ningún caso las trágicas consecuencias que estos enfrentamientos produjeron en algunas ciudades de la península.

Cabe destacar en este aspecto del orden público, el asalto sufrido por el Banco de Bilbao de la ciudad, el día 1 de abril de 1936, en el que cuatro individuos pistola 
en mano, se apoderaron de algo más de 80.000 pesetas, dándose a la huida en un automóvil que tenian preparado. El hecho puede considerarse desligado de planteamientos políticos, ya que los autores confesaron en el momento de su detención que pensaban huir a la zona Francesa a gastar lo obtenido. Posteriormente, al celebrarse el juicio, adujeron que iban a entregar el producto del atraco al Socorro Rojo Internacional.

Como en el resto del territorio nacional, se realizan en Melilla gran número de mítines y actividades por parte de Partidos y Asociaciones Políticas, a veces con terminología muy exaltada, exigiendo la rápida aplicación de medidas por parte del Gobierno, mayor rapidez en la aplicación del pacto del Frente Popular, rápida exigencia de responsabilidades, etc.

Toda esta actividad finalizó en la ciudad el 17 de julio de 1936 viernes, a las tres de la tarde, en que el coronel Solans y otros dos jefes detuvieron al General Romerales con legionarios y regulares concentrados a tal efecto, proclamando el estado de guerra. 